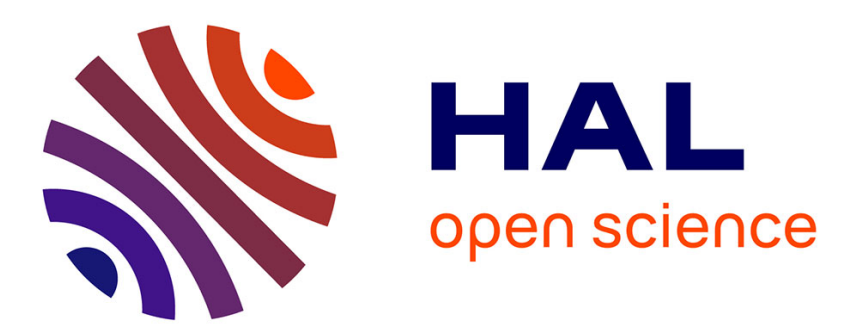

\title{
An initialisation methodology for ocean energy converter dynamic models in power system simulation tools
}

\author{
Sara Armstrong, Darren Mollaghan, Anne Blavette, Dara O 'Sullivan
}

\section{To cite this version:}

Sara Armstrong, Darren Mollaghan, Anne Blavette, Dara O 'Sullivan. An initialisation methodology for ocean energy converter dynamic models in power system simulation tools. 47th International Universities Power Engineering Conference (UPEC), 2012, London, United Kingdom. 10.1109/UPEC.2012.6398685 . hal-01265992

\section{HAL Id: hal-01265992 \\ https://hal.science/hal-01265992}

Submitted on 12 Jul 2016

HAL is a multi-disciplinary open access archive for the deposit and dissemination of scientific research documents, whether they are published or not. The documents may come from teaching and research institutions in France or abroad, or from public or private research centers.
L'archive ouverte pluridisciplinaire HAL, est destinée au dépôt et à la diffusion de documents scientifiques de niveau recherche, publiés ou non, émanant des établissements d'enseignement et de recherche français ou étrangers, des laboratoires publics ou privés. 


\section{An Initialisation Methodology for Ocean Energy Converter Dynamic Models in Power System Simulation Tools}

\author{
Sara Armstrong \\ Hydraulic and Maritime \\ Research Centre, \\ University College Cork \\ s.armstrong@ucc.ie
}

\author{
Darren Mollaghan \\ Hydraulic and Maritime \\ Research Centre, \\ University College Cork \\ d.mollaghan@ucc.ie
}

\author{
Anne Blavette \\ Hydraulic and Maritime \\ Research Centre, \\ University College Cork \\ anne.blavette@umail.ucc.ie
}

\author{
Dara O'Sullivan \\ Hydraulic and Maritime \\ Research Centre, \\ University College Cork \\ Dara.OSullivan@ucc.ie
}

\begin{abstract}
Environmental concerns, coupled with dwindling fossil fuel supplies, and growing government support, have resulted in increasing amounts of electricity generated from renewable energy. As the number of these installations rise, their influence on the behaviour of the electrical power system becomes more apparent. Transmission System Operators (TSO) carry out power system dynamic simulations in order to investigate the effect of renewable energy systems on the stability and reliability of the grid under varying operating conditions. Correct initialisation is an essential step in the dynamic model. This paper describes a three step methodology for correct initialisation of power systems dynamic model for an ocean energy system. The methodology is validated using DIgSILENT Power Factory simulations.
\end{abstract}

Index Terms-- Grid connection, power system simulation, renewable energy systems.

\section{INTRODUCTION}

The level of installed renewable energy capacity is constantly growing. These systems are characterised by intermittent power generation, presenting a unique challenge for grid connection as the integration of increasing proportions of renewable energy systems affects the stability and operation of the grid. Typically, power system simulation tools such as DIgSILENT Power Factory and PSS/E, among others, are used to analyse the dynamic behaviour of grid connected systems during normal operation and grid fault events. New grid code requirements are emerging, making the provision of dynamic power system simulation models mandatory for grid connection of renewable energy systems greater than 5MW [1,2]. These models allow the TSO to certify that the connection and operation of the proposed system operates within the grid code requirements under varying operating conditions.

Initialisation represents an important step in any dynamic simulation, and can be a difficult task $[3,4]$. It involves the calculation of the initial conditions of the renewable energy system dynamic simulation from load flow data.

This paper describes a three step methodology for correct initialisation of power systems dynamic simulations. DIgSILENT Power Factory is used to illustrate the methodology, provide results, and demonstrate the necessity for initialisation. The example system used is a grid connected ocean wave energy converter system. This is a particularly important issue for ocean wave energy due to its wide ranging fluctuation levels over short time periods. However, the described methodology is generic; applicable wherever the generating power source is intermittent.

The paper is divided into the following sections; in Section II, the implications of improper initialisation, and the issues it creates for transmission system operators are described. Previous approaches that have dealt with initialisation for power systems simulation tools such as DIgSILENT Power Factory and PSS/E are also detailed. Section III provides a brief introduction to the structure of the ocean wave energy system and describes the three step methodology for correct initialisation of the system. The initialisation strategy is then illustrated using DIgSILENT Power Factory power system simulations.

\section{IMPLiCATIONS OF POOR INITIALISATION PRACTICE}

The provision of power system dynamic models allows the TSO to investigate how the installation of new renewable energy systems will interact with the grid, and what, if any, remedial design work needs to be carried out in order to maintain grid stability. Additionally, validated dynamic power system models are used to perform the future grid planning and reinforcement necessary to meet the rising levels of installed renewable energy established by government targets. Power system dynamic models must provide the TSO with details of how quantities such as the system active power, reactive power and compensation, turbine speed, and generator electrical parameters will perform under normal and faulted conditions.

Initialisation of the dynamic model is an essential step in the dynamic modelling process. Establishing correct initial conditions for the dynamic models ensures that the steady state created at the beginning of the simulation is a true representation of the operating conditions, and not a result of improper initialisation. It also avoids unwanted transient 
behaviour at the beginning of the simulation, which increases the time at which the system reaches steady state, and may interfere with the simulation if a real transient on the grid, such as a fault, were to occur [3]. Correct initialisation reduces the possibility of numerical instability occurring before an equilibrium is reached.

The issues faced by a TSO as a result of poor initialisation practice in wind turbine dynamic models were documented in [5]. It was observed that simulation problems tended to occur when the dynamic models were configured to operate below their full rated output, due to a lack of testing and analysis during model development and coding. Inadequate resolution in lookup tables was also cited as a source of error. The consequences of these initialisation issues may be shown graphically in Fig. 1 and 2, where a wind turbine model is initialised at 0.203 per unit (p.u.) output power, and 1.05 p.u. voltage under normal operating conditions. Following the initialisation of the wind turbine model, two unwanted phenomena can be seen. Firstly, an initial transient period may be seen which takes almost 0.4 seconds to stabilise, and secondly, the parameters settle at values different from those originally proposed above. These types of dynamic model initialisation issues must be addressed to allow the TSO to accurately study the impact of renewable energy systems on the stability of the power system network.

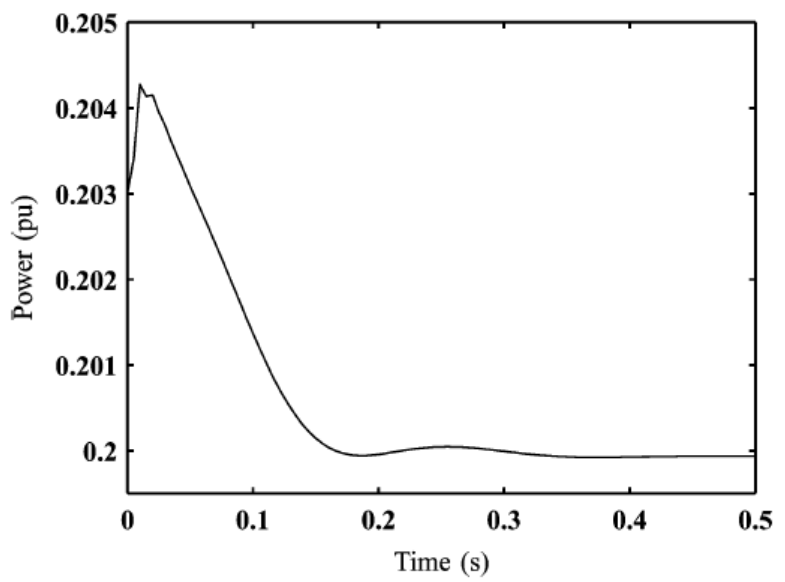

Fig. 1 Power output of wind turbine model following initialisation [5]

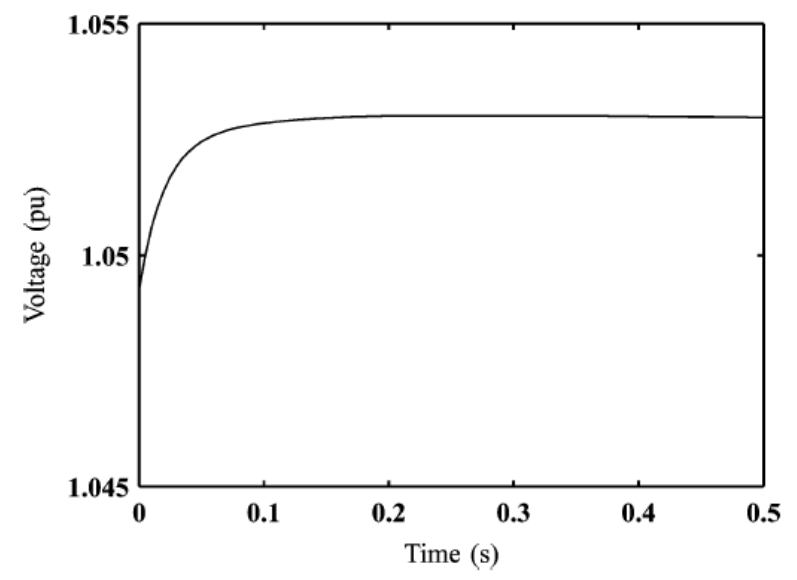

Fig. 2. Wind turbine model bus voltage following initialisation [5]

\section{A. Previous Initialisation Methods}

Two initialisation approaches have been previously described for wind energy systems; Method 1 [3] uses bidirectional initialisation, while Method 2 initialises the dynamic model in one direction [4]. The initialisation directions are shown in Fig. 3, which depicts the typical components of a grid connected wind energy system. The model inputs include the initial pitch angle, initial wind speed, and from the grid side; initial generator power, voltage, current and speed, reactive power, and initial capacitor bank status information.

The initialisation issues of a blade angle controlled wind turbine with a squirrel cage induction connected directly to the grid are considered in Method 1, using DIgSILENT Power Factory [3]. This method incorporates bidirectional initialisation; the program is initialised from the wind turbine to the grid by inputting an initial wind speed and blade angle, while it is also initialised from the grid connection via the load flow analysis. The two initialisation directions meet each other at a certain model component in the program flow. For correct initialisation, the non-electrical input data from the wind turbine side must correspond to the load flow electrical power from the grid side, based on the static power curve from the wind turbine and on the generator efficiency. Any potential mismatch in these signals is avoided by placing the meeting point of these two signals in a component model whose signals or states can absorb the transients. This occurs between the aerodynamic model and the mechanical model of the wind turbine, where the large inertia of the rotor absorbs the transients.

An alternative approach is given in Method 2 using the PSS/E power simulation tool for three types of wind turbine systems; a constant speed wind turbine, variable speed wind turbine with doubly fed induction generator, and a variable speed wind turbine with a direct drive synchronous generator. The latter two types include back to back converters. In this approach, the initialisation process follows one direction; from the generator to the input wind speed data. The initial conditions of the wind turbine system are determined based on the load flow outputs of the generator, which in turn is used to initialise the mechanical model of the turbine and shaft, which is then used to calculate the initial wind speed.

Method 1 described a wind system directly connected to the grid. However, the proposed ocean energy system incorporates back to back converters (Further details of the system setup will be given in Section III). These components introduce additional control signals, which specify operating points for parameters such as the reactive power, DC voltage, and generator voltage. These extra control signals can introduce discrepancies between the initial control signals and the load flow values, causing more initialisation issues not experienced in a directly connected system. Furthermore, the ocean energy system may not use the large inertia of the rotor to avoid the mismatch in the signal flow as described in Method 1. In Method 2, three approaches were 


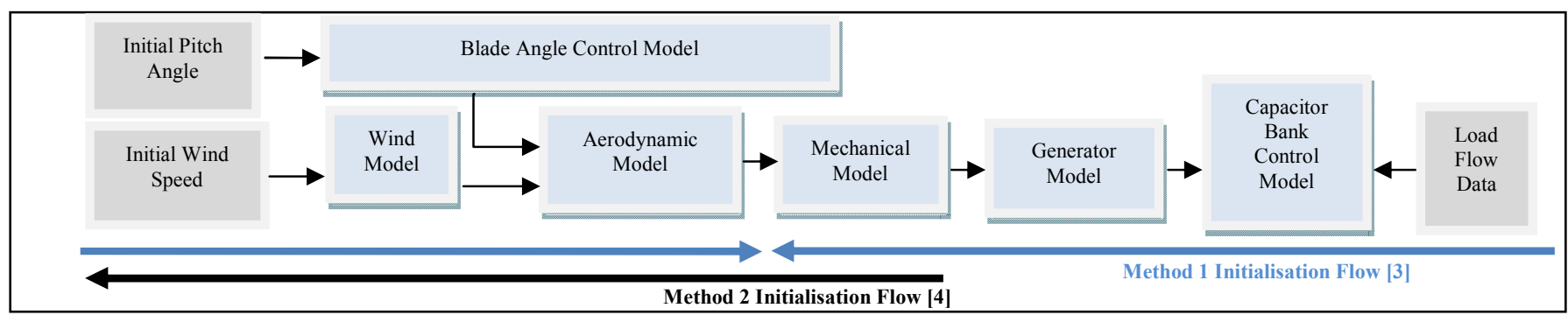

Fig. 3. Typical structure of a wind energy system showing the initialisation approaches of [3] and [4]

described; two of which included back to back converters. However, in this initialisation method, if the wind turbine is set to operate below the nominal power of the generator, the power - speed control law is used to determine the initial rotor speed of the turbine, which in turn is used to determine the initial wind speed, and associated generator data. This approach may not be used in the proposed ocean energy system. This is as a result of constraints imposed on the initial values of the generator speed by the power systems simulation package, DIgSILENT Power Factory, which sets the initial generator speed to 1 p.u. Subsequently, it is necessary to develop a new initialisation methodology for a grid connected ocean energy system, which is described in the following section.

\section{OCEAN ENERGY SYSTEM STRUCTURE}

The typical inputs and energy conversion processes of an ocean wave energy system are given in Fig. 4. They are defined as follows:

1) Wave Source Data: This input data is comprised of a time series of wave height elevation data.

2) Primary Power Capture (PPC): This process describes the means through which the ocean energy device interacts with the energy source, transferring energy from the waves or tidal currents to a medium which can be captured by the Prime Mover Unit. Some ocean wave energy PPC examples include oscillating water columns, and overtopping devices. This model uses a system identification process developed using test data to determine the PPC from the wave source data input.

3) Energy Storage Unit: This module is used to smooth the high variability in the primary power capture output, thus improving the power quality produced by the device. In the proposed ocean energy system, the energy storage effect is modelled using a low pass filter.
4) Prime Mover Unit: This converts the captured energy into to a more useful form of energy, usually mechanical energy, which can be connected to a generator, which in turn produces electrical energy. A turbine is used in this example; hence the mechanical power input to the generator will be referred to as the turbine power hereafter. The actual power generated by the prime mover depends on the efficiency of the turbine. This efficiency is determined from the turbine speed by using the speed-efficiency characteristic curve, typically available from the turbine manufacturers.

These system components are modelled in DIgSILENT Power Factory, where the red arrows in Fig. 4 show the initialisation flow which meets in the Prime Mover Unit module. The input data to the dynamic model is as follows:

1) Electrical system input: The generator side back to back converter power is entered by the user in the Power Factory model. This in turn calculates the initial values of the connected models. The signals determined from the load flow analysis include the generator active and reactive power, current, speed, turbine power, among others.

2) Non-electrical input data: (From wave to grid connection) Wave height elevation data.

The electrical system of the grid connected ocean energy system is shown in Fig. 5. It consists of a synchronous generator, back to back converter, and two transformers. The generator side PWM converter is responsible for the DC bus voltage and the reactive power control, while the generator side converter controls the active power and generator voltage. It also includes two series reactors connected to the synchronous generator and the grid connection (not shown). These are used for filtering purposes, and may also provide protection against excessively large currents under shortcircuit or transient conditions.

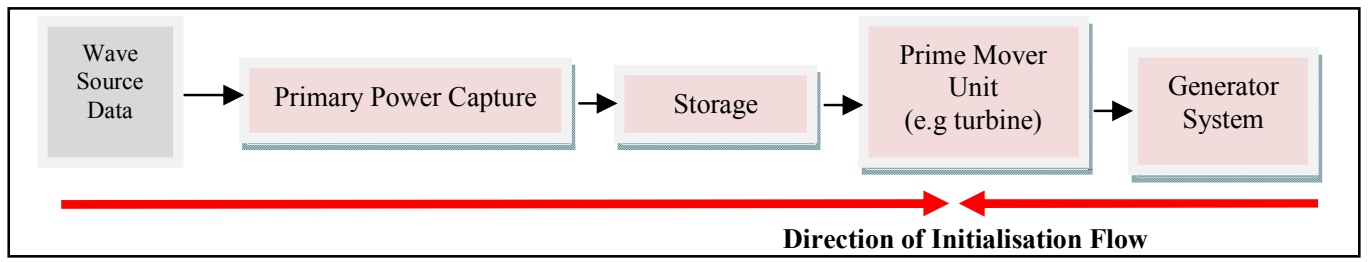

Fig. 4. Energy conversion processes of an ocean energy system 


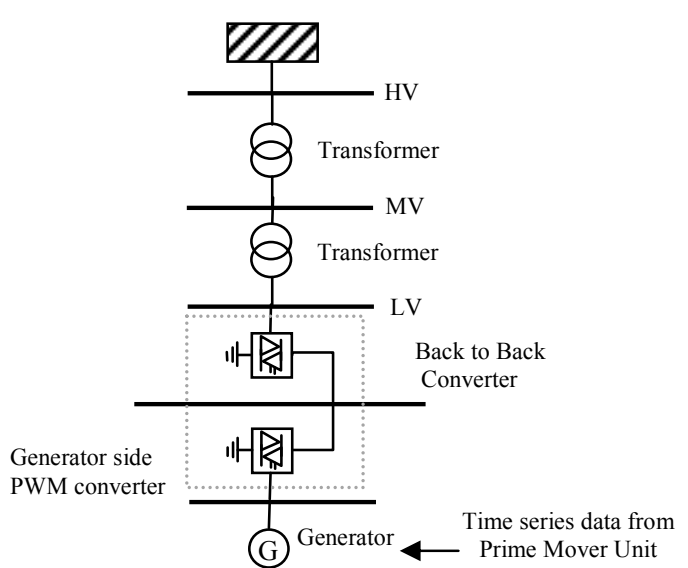

Fig. 5. Ocean energy electrical network

\section{NEW INITIALISATION METHODOLOGY}

This section describes the methodology to initialise the dynamic power systems model for an ocean energy system. It may be broadly categorised into three areas:

1) Section $A$ - Determining the initial conditions for a load flow analysis: This section determines the correct selection for the load flow value for the initiation of the dynamic simulation in order to avoid large transients at the beginning of the simulation.

2) Section B - Determining initial equations in DIgSILENT Power Factory Dynamic Simulation Language (DSL): This section looks at the user defined initial equations used in DSL models that are used to initialise models, and also looks at recommendations made by Power Factory for correct initialisation.

3) Section C - Mismatch in Program Simulation Flow (Offset Removal): In a scenario where the initialisation flow from two opposite directions causes a mismatch in the model to occur, and where there is no model component allowing these transients to be absorbed as described in [3], offset removal equations must be included to eliminate this initial transient.

\section{A. Determining Initial Conditions from Load Flow Analysis}

Power system simulation tools use a load flow study as a starting point for dynamic modelling. The parameters for the load flow analysis must be chosen carefully so that the transmission system voltages are within the specified tolerances, and that the system converges with only a small mismatch. Additionally, this first step is necessary in order to avoid large transients at the beginning of the simulation. An example of this is given in Fig. 6 and 7, where the effect of using two different load flow generator power outputs $(1.365$ MW and 0.5 MW respectively) on the initial conditions of the turbine power is shown. Evidently, from Fig. 6, the initial value of the turbine power varies greatly from the average value, and a large deviation from the initial value occurs at the beginning of the simulation. This can be avoided by choosing a more appropriate initial load flow value, as done in Fig. 7. This may be done by choosing the appropriate value for the power of the generator side PWM converter for the load flow analysis (referred to as "Active Power Setting" in
Power Factory). The flowchart for this methodology is shown in Fig. 8. As previously mentioned (Section III), the PPC is calculated from the wave source input data using a system identification process, and an average PPC value is then found. The actual power generated depends on the efficiency of the turbine. The initial turbine efficiency is determined from the initial turbine speed ( 1 p.u.) by using a speedefficiency characteristic curve, giving $60 \%$ in this example. This gives the turbine power, which is then converted to per unit values. In order to ensure that the turbine power begins at this value, the generator side $\mathrm{PWM}$ converter, $\mathrm{P}_{\text {conv ref, must }}$ be set at:

$$
P_{\text {conv_ref }}=\frac{\mathrm{PPC}_{\text {mean }} \eta_{\text {turbine }}{ }^{\cos \varphi} \text { gen }}{P_{\text {nom gen }}}
$$

where $\mathrm{PPC}_{\text {mean }}$ is the average primary power capture, $\eta_{\text {turbine }}$ is the efficiency of the turbine, $\cos \varphi_{\text {gen }}$ is the generator power factor, and $\mathrm{P}_{\text {nom gen }}$ is the generator base power.

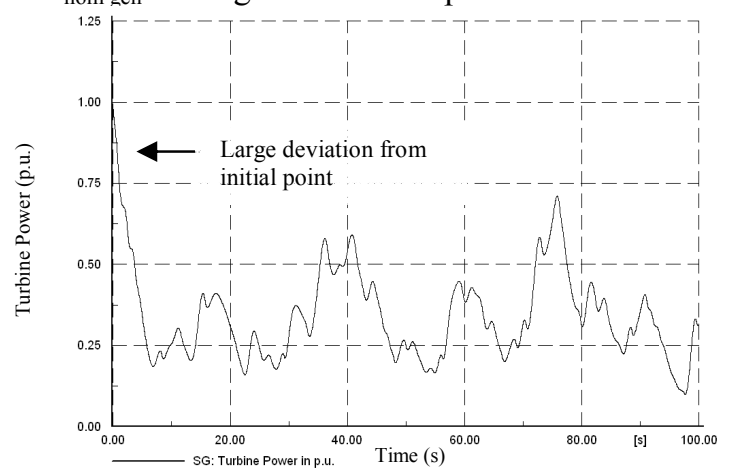

Fig. 6. 1.365MW load flow starting point

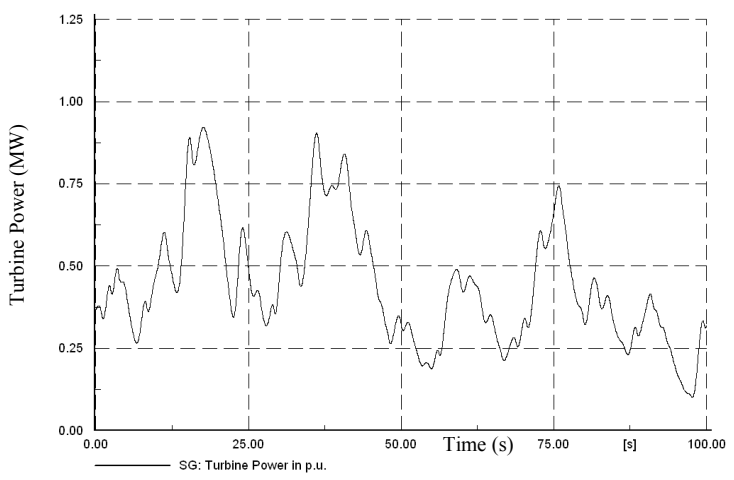

Fig. 7: 0.5MW load flow starting point

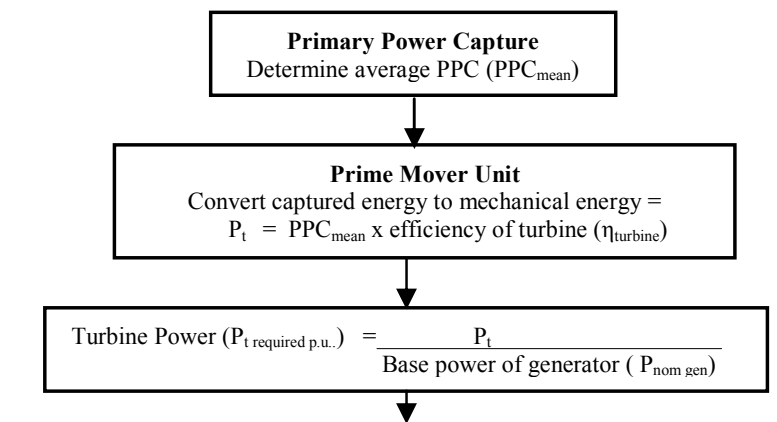

Setting for Active Power of Generator Side PWM Converter $\mathrm{P}_{\text {conv ref }}=\mathrm{P}_{\mathrm{t} \text { required p.u. }} \times \mathrm{P}_{\text {nom gen }} \mathrm{x}$ Generator power factor $\left(\cos \varphi_{\text {gen }}\right)$

Fig. 8. Flowchart for determining the load flow initial value 
B. Implementing Initialisation Equations with the Dynamic Simulation Language (DSL)

Power Factory automatically performs the initialisation of the built-in electrical models in the load flow study, such as the generator. Only the initial equations of the user defined models need to be included, for example, the primary power capture, energy storage or prime mover unit components shown in Fig. 4. This is done using the DSL language, which allows the user to create new blocks either as modifications of existing models or as completely new components. DIgSILENT initialises one model at a time, using the information obtained from the previous model; therefore, once the load flow calculation is performed, and all the electrical models are initialised, the initialisation of the nonelectrical user defined models is carried out. A key step in this stage of the initialisation methodology is to establish the sequence in which the models should be initialised. The models should be initialised from right to left; the opposite direction to the simulation flow. The initial values of the output are calculated from the load flow analysis, and the values of the state variables and other signals are determined from these load flow values.

In addition, several initialisation requirements are specified by Power Factory [6]:

1) The initial conditions must correspond to a steady state solution, as determined by the load flow calculation (the derivatives are set to zero).

2) All state variables used within the user defined models must be initialised. If these variables are not initialised properly, they will not stay at their initial value at the beginning of the simulation, which may lead to unwanted transients.

3) All unknown input and output signals must be initialised. Unknown signals are defined as those that are not connected to DIgSILENT's in-built models, or other blocks, which initialise the signals.

4) The inputs to all integrators should be zero.

5) In transfer functions, s should be equal to 0 .

\section{Mismatch in Program Simulation Flow - Offset Removal}

Even with an improved initial value from load flow conditions (Section IV, A), a mismatch may occur in the dynamic model where the non-electrical input from the renewable energy source does not correspond to electrical power from the grid side, as determined by the load flow. An example of this is shown in Fig. 9, which shows the generator side PWM controller connected to the PWM converter, with associated sensors for measuring generator speed and active power.

The reference power refers to the value specified by a control law derived from the generator speed, as shown in Fig. 10. The initial value of this reference power is $0.4 \mathrm{MW}$, because the initial generator speed is set to 1 p.u.. This is a result of constraints imposed on the initial values of the generator speed by the power systems simulation package. The initial equations of the PWM converter controller
DIgSILENT model state that the reference power should be equal to the measured power. Therefore, therefore a mismatch occurs at the beginning of the simulation, (see Results, Section V), due to the fact that the measured power is set by the load flow, while the reference power is defined by the user defined speed control law. In this ocean energy system, it is not possible to absorb these mismatch transients with model components, for example the large inertia of the rotor in Method 1 (Section II, B). Therefore, it is necessary to include an offset parameter in the control law in the user defined model to eliminate this mismatch.

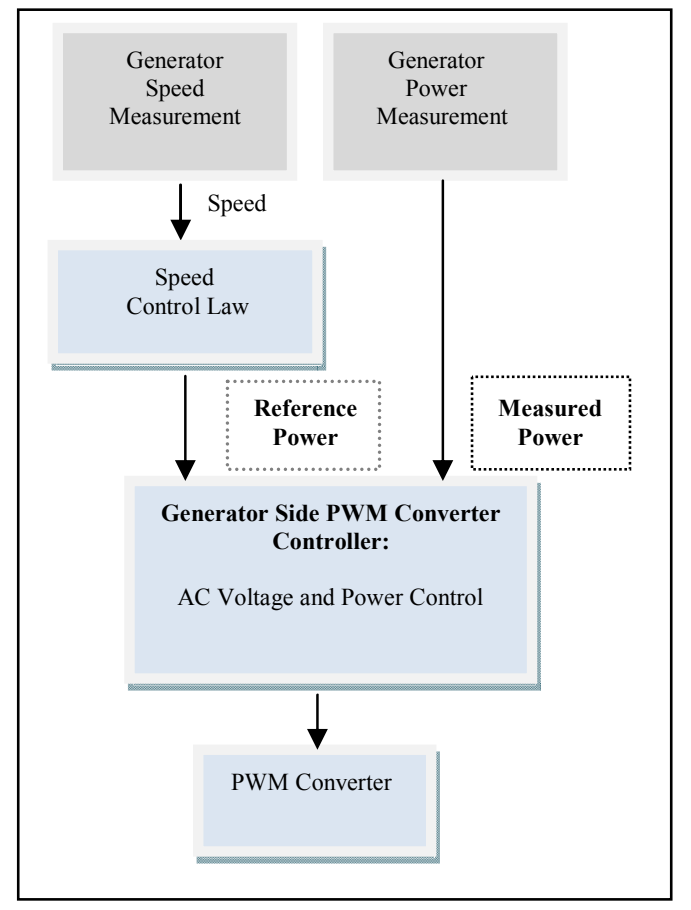

Fig. 9. Mismatch of measured and reference power signals in the generator side PWM convertor control section of the electrical network

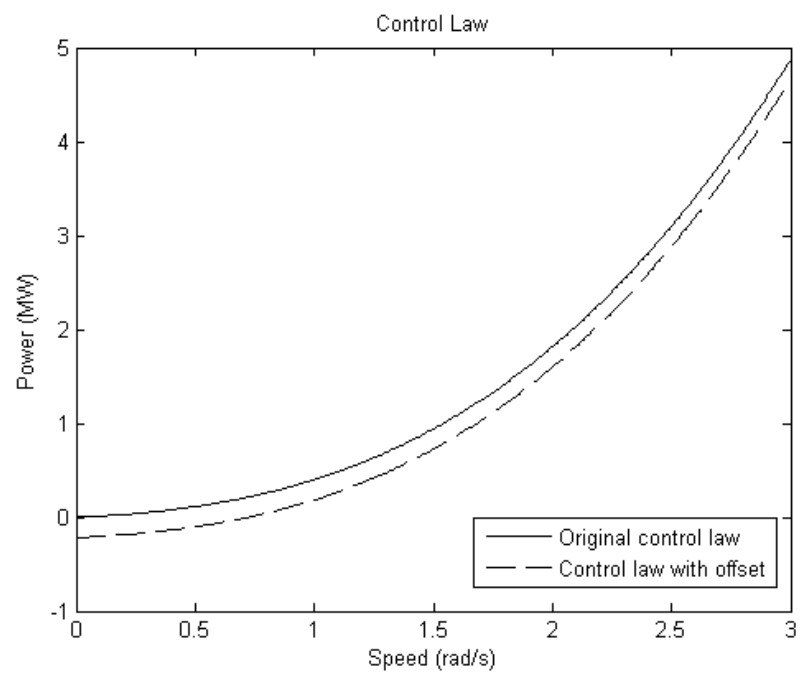

Fig. 10. Control law for specifying the generator power in relation to the speed 
However, the issue with including the offset is that the reference power specified by the control law will always contain this offset value, as seen by the dashed line in Fig. 10. (The value of the offset will depend on the initial generator power setting). Therefore, it is necessary to remove this variable using parameter events created in Power Factory. This ensures that the value specified by the speed control law is properly implemented.

\section{RESULTS}

In this section, the initialisation methodology is demonstrated using DIgSILENT Power factory simulations. Fig. 11 and 12 show the impact of unsuitable initialisation; specifically, using a poor choice of initial condition for the load flow, and the absence of offset removal, respectively. In Fig. 11, a transient may be seen at the beginning of the simulation, while in Fig. 12, the mismatch in the reference and measured power signals is evident. A smaller time scale is used in this graph to allow the mismatch to be seen more clearly.

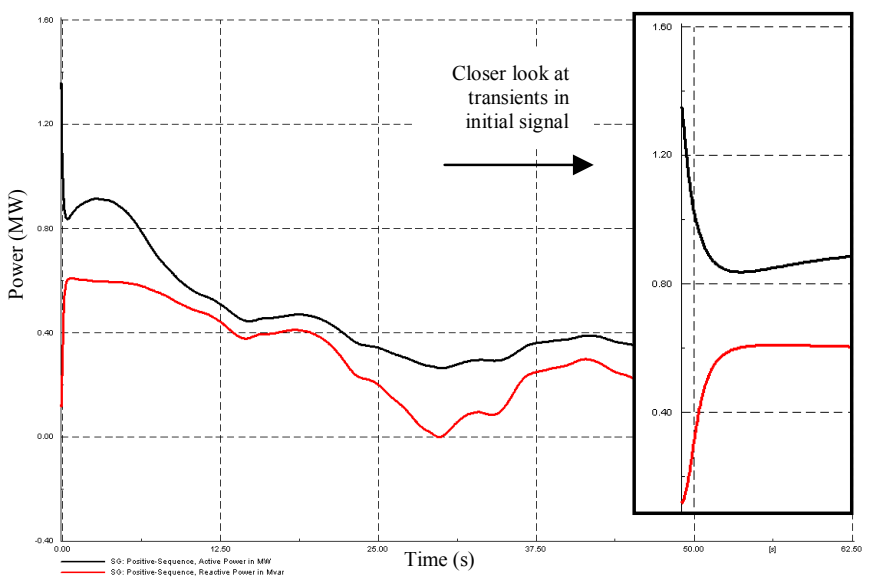

Fig. 11. The effect of unsuitable choice of initial conditions for load flow analysis (black line: generator active power, red line: generator reactive power)

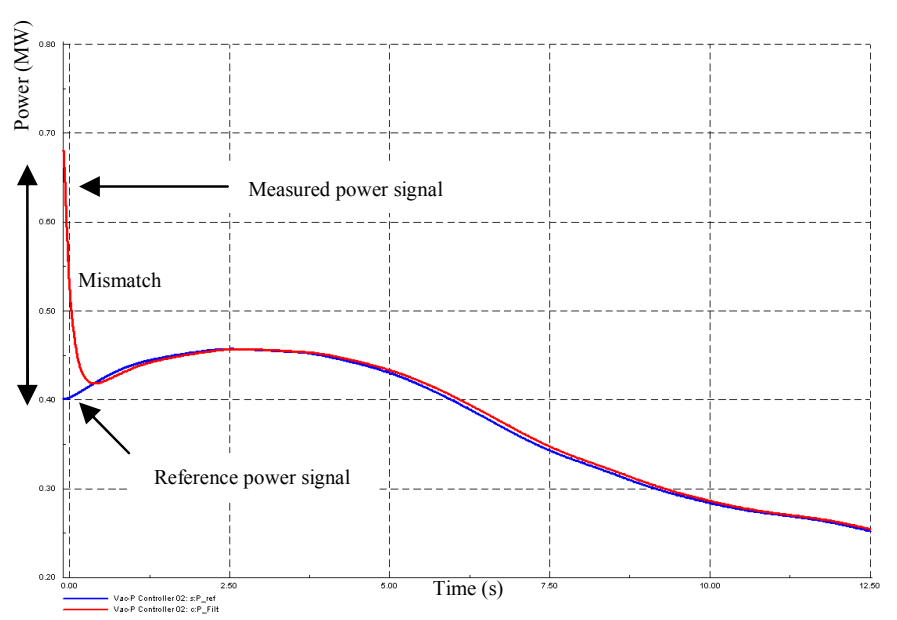

Fig. 12. Dynamic simulation model without initialisation showing the mismatch between the initial values of the active power (red line) and reference power (blue line)

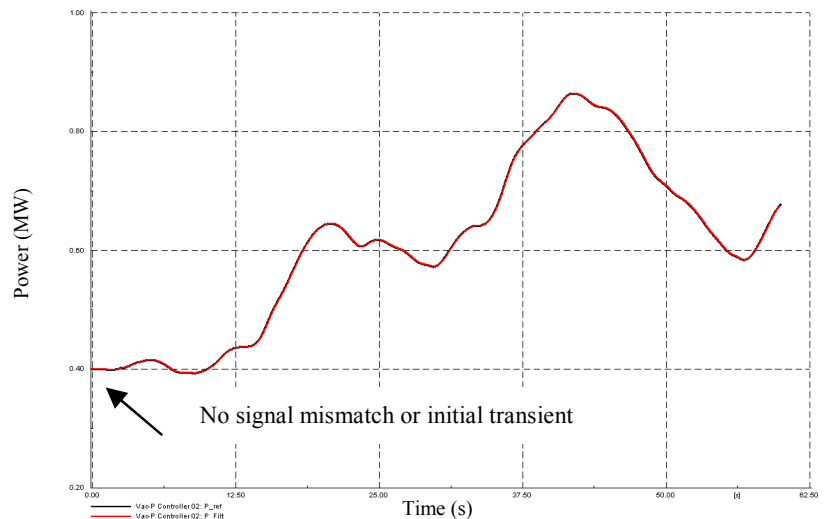

Fig. 13. Initialised dynamic simulation showing the overlapping reference (black line) and measured generator power (red lines).

These initialisation issues are rectified in Fig. 13, where the initialisation steps of Section IV, A and C, are implemented. (The steps detailed in Section B; initial equations in the DSL language, may not be demonstrated graphically, because if this step is carried out inadequately, it is not possible to run Power Factory simulations.) In comparison to Fig. 11 and 12, it can be seen that the unwanted transients at the beginning of the simulation have been eliminated.

\section{CONCLUSIONS}

This paper presented a three step methodology to determine the initial conditions of a dynamic model for a grid connected renewable energy system. An ocean energy system modelled in DIgSILENT Power Factory was used to demonstrate the methodology. The steps included determining the initial conditions for a load flow analysis, establishing initial equations in Power Factory Dynamic Simulation Language (DSL), and removing the mismatch in simulation flows.

\section{ACKNOWLEDGEMENTS}

The authors would like to thank Enterprise Ireland for the funding of this work. The work of Dara O'Sullivan was supported by the Charles Parsons Award from Science Foundation Ireland (Grant 06/CP/E003).

\section{REFERENCES}

[1] A. Morales, "Advanced grid requirements for the integration of wind farms into the Spanish transmission system", IET

Renewable Power Generation, vol. 2, no. 1, pp. 47-59, 2008.

[2] "The Grid Code", Issue 4, Revision 10, Jan 2012, National Grid, http://www.nationalgrid.com/uk/Electricity/Codes/gridcode/

[3] A.D. Hansen, "Initialisation of grid-connected wind turbine models in power systems simulations", Wind Engineering, vol. 27, no. 1, 2003.

[4] J.G. Slootweg, H. Polinder, W.L King, "Initialisation of wind turbine models in power system dynamic simulations", IEEE Porto Power Tech Conference, 2001.

[5] Y. Coughlan, P. Smith, A. Mullane, M. O' Malley, "Wind turbine modelling for power system stability analysis - a system operator perspective", IEEE Trans. on Power Systems, vol. 22, pp. 929-936, August 2007.

[6] DIgSILENT Seminar Notes, "Dynamic Modelling (DSL) Workshop", March 2010, Gomaringen, Germany. 